
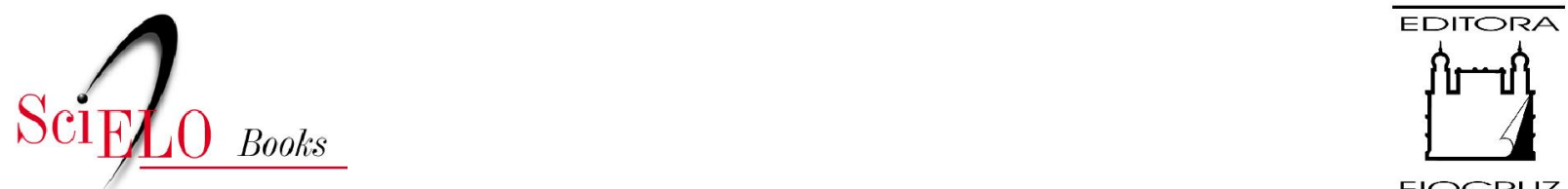

FIOCRUZ

\title{
1. A constituição do sujeito coletivo e a questão dos direitos humanos
}

\author{
Carlos Alberto Plastino
}

\section{SciELO Books / SciELO Livros / SciELO Libros}

PLASTINO, CA. A constituição do sujeito coletivo e a questão dos direitos humanos. In:

ACSELRAD, G. org. Avessos do prazer: drogas, Aids e direitos humanos [online]. 2nd ed. rev. and enl. Rio de Janeiro: Editora FIOCRUZ, 2005, pp. 17-33. ISBN: 978-85-7541-536-8. Available from: doi: $10.7476 / 9788575415368$. Also available in ePUB from: http://books.scielo.org/id/bgqvf/epub/acselrad-9788575415368.epub

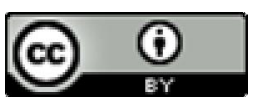

All the contents of this work, except where otherwise noted, is licensed under a Creative Commons Attribution $\underline{4.0 \text { International license. }}$

Todo o conteúdo deste trabalho, exceto quando houver ressalva, é publicado sob a licença Creative Commons Atribição 4.0.

Todo el contenido de esta obra, excepto donde se indique lo contrario, está bajo licencia de la licencia Creative Commons Reconocimento 4.0 . 


\section{A CONSTituição do Sujeito Coletivo e a Questão dos DiREITOS HUMANOS}

\section{Cartos Alberto Plastino}

\section{Para o Betinho}

saudades

O conceito do sujeito evoca duas acepções antagônicas. Sujeito é aquele que faz, que pratica ações e também que é titular de direitos (Cf. dicionário de Aurélio Buarque de Holanda Ferreira). Entretanto, o termo exprime também uma idéia praticamente oposta: sujeito é quem está obrigado, quem depende da vontade de outro, e ainda quem é escravo e quem está submetido. Temos, pois, duas significações evocando alternativamente a idéia de atividade e autonomia e a de submissão, escravidão e dependência. Na verdade, a língua exprime a complexidade do conceito, forjado em um longo e acidentado processo histórico. Na Antigüidade grega o termo subjectum evocava aquilo que constituía o substrato do mundo fenomênico, remetendo assim a uma idéia de mistério. A idéia de mistério, por sua vez, se referia àquilo que, não sendo apreensível pela razão conceitual, permanecia desconhecido.

Essa perspectiva mudará radicalmente com a modernidade. Ao longo de um vasto movimento caracterizado pelo racionalismo e o individualismo, o termo 'sujeito' passa a designar o homem, imbuído da tarefa de dominar a natureza por meio de sua razão e de seu trabalho. Há, entretanto, uma ambigüidade nessa relação entre o homem e a natureza. É que a concepção moderna faz do real uma máquina totalmente determinada, com suas leis de funcionamento potencialmente conhecíveis pela razão. Assim, a razão humana pode conhecer e dominar - esta é a tarefa atribuída às ciências e à técnica - o funcionamento do existente, incluindo aí a própria natureza humana. Porém, sendo o real pensado como totalmente determinado, é a idéia de necessidade que preside essa concepção, não a de liberdade. Talvez seja essa complexa 
concepção que se encontra na base da ambigüidade do termo sujeito. De um lado, como sujeito racional, ele é pensado como podendo ascender ao domínio total das leis que regem o real, tornando-se senhor delas e capaz de utilizar seu conhecimento para dominar a natureza e impulsionar o progresso. De outro lado, sendo a realidade totalmente determinada, o processo histórico se apresenta como 'necessário', não restando nessa concepção espaço para a criação e para a liberdade. Esta se limitaria, para repetir a famosa frase de Engels, a ser a consciência da necessidade. Nessa concepção, então, o homem é pensado como senhor de sua razão e de suas ações e, através delas, dominador do mundo e, ao mesmo tempo, como dependente das determinações rigorosas que estruturam o real. Como veremos, essa ambigüidade se apresenta com muita força no discurso hoje hegemônico. A oposição entre 'liberdade' e 'determinismo' e suas relações com o sujeito constitui um primeiro ponto a ser discutido.

Entretanto, o tema proposto para nossa reflexão neste texto refere-se ao sujeito coletivo. Convém vincular este conceito - ao interior do paradigma da modernidade - com o conceito de classe social cunhado pela teoria marxista. É sabido que, para Marx, os homens são os demiurgos de sua própria história, porém, não como indivíduos mas como sujeitos coletivos. $\mathrm{Na}$ sociedade capitalista o protagonismo no processo de transformação social é atribuído à classe proletária. A transformação da classe em si em classe para si supõe, na perspectiva marxista, a eliminação da alienação e, em conseqüência, o aceso do proletariado à compreensão racional da realidade, momento decisivo na sua configuração como sujeito coletivo revolucionário. Este rico conceito marxista é tributário, de um lado, da realidade da sociedade capitalista tal como existia na época de Marx e, de outro, da perspectiva característica da modernidade, segundo a qual o sujeito era definido unilateralmente a partir de sua racionalidade. A questão central aqui é discutir se o papel de sujeito coletivo deve continuar a ser atribuído à classe social ou, alternativamente, se é preciso pensar em sujeitos coletivos plurais. Este é o segundo ponto que interessa aqui considerar.

O terceiro ponto relacionado ao tema deste artigo refere-se aos direitos humanos. Sua emergência coincide historicamente com a consolidação da idéia moderna de sujeito e se dá no bojo de uma concepção do mundo e da sociedade centrada no indivíduo. Articulada com as concepções centrais da modernidade, a idéia dos direitos humanos se consolida quando, com o sucesso da revolução política, igualdade, liberdade e fraternidade tornam-se, no discurso político, valores fundamentais. Isso constituiu uma mudança signi- 
ficativa. Antes da modernidade, a sociedade era pensada não em termos de igualdade, mas em termos de diferença (diferença entendida como negação da igualdade). O poder de um senhor feudal, na idade pré-moderna, sustentavase no (pretenso) fato de ele ser diferente, isto é, superior. A própria idéia do direito, nessa época, se organizava em torno dos 'privilégios'. Este termo tem hoje uma conotação negativa, aludindo a um tratamento especial injustificado e, portanto, injusto. Sem dúvida é isso mesmo, e a própria origem do termo o indica. Privilégio significa, originariamente, lei privada, isto é, conjunto de normas aplicáveis a algumas pessoas e não a todas. Um exemplo atual, no Brasil, é a vigência de tribunais especiais para os policiais militares, que, assim, ao invés de serem julgados pela mesma justiça que julga todos os cidadãos, desfrutam de um tribunal especial. Enfim, o exemplo serve não apenas para ilustrar o quanto estamos longe de uma verdadeira modernidade, mas, sobretudo, para mostrar que a idéia de igualdade apenas recentemente se impôs como valor. Um valor que, mesmo restrito ao nível da ideologia, exigiu lutas e sacrifícios prolongados para ser reconhecido. Entretanto, vinculada à questão dos direitos humanos, a igualdade como valor, embora necessária, não é suficiente. É preciso completá-la, como veremos, com a idéia de valor da diferença - idéia que nada tem a ver com a de privilégio ou superioridade, mas que alude ao direito de cada homem à singularidade. Este é o terceiro ponto a discutir aqui.

A discussão - mesmo que necessariamente sucinta - das três questões assinaladas exige considerá-las no quadro histórico de sua emergência. O que significa discutir primeiro o paradigma no qual essas questões foram pensadas. Paradigmas são formas historicamente produzidas de conceber o real e o processo do conhecimento. O paradigma da modernidade está centrado no pressuposto da racionalidade. Convém distinguir a racionalidade pressuposta no objeto e a racionalidade pressuposta no sujeito. Pela primeira postula-se que o real - tanto o real natural como o social e humano - está organizado conforme leis rigorosas de determinação, constituindo, em conseqüência, uma ordem necessária. Assim a realidade seria em última instância simples, e sua compreensão redutível a leis cujo conhecimento é acessível à razão humana. É sobre essa crença - sustentada no fantástico sucesso obtido pela física moderna ou newtoniana, assim como no pressuposto da racionalidade do sujeito - que foi construída a idéia do progresso: o conhecimento das leis que regem o real por parte do sujeito racional (ciência) tornaria possível a manipulação desse real (técnica) de maneira a atingir os objetivos humanos e garantir um progresso permanente. Nessa formulação está obviamente implícita a segun- 
da vertente do racionalismo, a subjetiva, segundo a qual o homem, como sujeito racional, poderia potencialmente ascender ao conhecimento das leis que regem o real. Há aqui, como se verá, ao mesmo tempo, uma exorbitância e uma mutilação na concepção do homem. De um lado, atribui-se a ele a capacidade de obter o conhecimento da verdade do real, de maneira a permitir-lhe, potencialmente, um domínio total de tal conhecimento. E ao mesmo tempo uma mutilação, na medida em que o homem é definido apenas pela sua racionalidade, com exclusão dos aspectos emocionais e afetivos.

Convém insistir na idéia de que esse paradigma - como todos os outros - é uma produção histórica. E acrescentar que o próprio desenvolvimento das ciências a que ele deu origem encarregou-se de contestá-lo. Elas nos mostram hoje, com efeito, que a realidade, longe de apresentar a simplicidade de leis rigorosas e universais, evidencia uma enorme complexidade. Ademais, ao invés da ordem que era pressuposta, é preciso postular a coexistência de ordens diferentes, pautadas por princípios diferentes e por momentos de caos que se necessita compreender como matriz possível de novas e inéditas ordenações. Essas novas ciências nos falam ainda não de uma natureza inerte, passivamente submetida a leis eternas, mas de uma natureza viva, autocriativa. Assim, não é apenas o paradigma que é histórico. A própria realidade é pensada hoje como histórica. Obviamente, é impossível sequer resumir aqui esse rico processo de transformação paradigmática. Convém, entretanto, salientar que o paradigma fundador da modernidade atravessa uma profunda crise e que esta crise paradigmática constitui um dos aspectos centrais da crise de civilização que estamos vivendo.

Outro aspecto dessa crise de civilização reside no processo histórico de evolução das sociedades modernas, condensando as crises econômica, social, política e cultural hoje vigentes. A consideração dessa crise, assim como a do paradigma moderno, me parece imprescindível para nos aproximar de uma resposta das questões levantadas. Mais uma vez é necessário frisar que, considerando o âmbito das questões abordadas, só será possível desenvolver aqui algumas idéias gerais sobre o tema.

A modernidade demonstrou-se incapaz de cumprir suas promessas e, ao que tudo indica, na trilha atual, ela será cada vez mais incapaz de fazê-lo. Apesar do fantástico progresso científico e técnico que tornou possível, ela não conseguiu tornar realidade os valores de igualdade, fraternidade e liberdade, de democracia e vigência dos direitos humanos que levantou como bandeira. É obvio que não pretendemos negar os progressos efetivamente realiza- 
dos. Todavia, uma análise mesmo sucinta da realidade contemporânea impede qualquer complacência a esse respeito. Senão, vejamos algumas das características mais evidentes da realidade contemporânea.

Conforme o projeto da modernidade, o progresso da ciência e da técnica permitiria aos homens alçarem-se à condição de senhores do mundo, dominando a natureza para pô-la ao serviço dos objetivos humanos. A razão humana permitiria, assim, manipular o mundo natural e social para atingir os ideais proclamados pela modernidade. A razão instrumental estaria subordinada à razão substantiva, e a ciência e a técnica, subordinadas aos objetivos livre e racionalmente fixados pela humanidade. O processo histórico, entretanto, não confirmou essas previsões. No contexto da organização capitalista da sociedade, foi a razão instrumental que se tornou hegemônica, cabendo à lógica da máquina produtiva ditar as regras no convívio social. Na lógica individualista do capitalismo, a maximização dos interesses individuais resultaria na melhor ordenação social possível. Obviamente essa concepção se sustenta em uma concepção da natureza humana que pensa o homem como movido apenas pelo seu interesse egoísta. A natureza, por sua vez, é concebida - de acordo com o paradigma moderno - como eterna e inerte, submetida a rigorosas determinações. Como se verá depois, essa concepção não é confirmada pelos saberes contemporâneos sobre o homem (psicanálise, psicologia analítica) nem pelas ciências contemporâneas.

Essa lógica impôs às relações do homem com a natureza e dos homens entre si a marca da dominação, não a da fraternidade. A dominação da natureza, através de uma febril atividade predatória, levou ao atual desastre ecológico, sobre o qual - dada sua evidência - não é preciso alongar-se aqui. A dominação do homem sobre o homem, por sua vez, resultou do desigual acesso ao poder e aos recursos produtivos. Essa lógica centrada no individualismo gerou, assim, o contraste entre o fantástico desenvolvimento da racionalidade parcial e o não menos fantástico - e assustador - crescimento da irracionalidade global. A racionalização dos processos produtivos - orientada centralmente pela procura do lucro - teve como conseqüência o crescimento da desigualdade na distribuição do produto e do desemprego. E ainda a irracionalidade na determinação do conteúdo da produção - na escolha do tipo de bens produzidos - comandada não pelas necessidades humanas mas pela configuração da demanda, ela própria determinada pela desigual distribuição da renda e pela manipulação operada pela propaganda. Consideremos isso um pouco mais detalhadamente. 
É inquestionável que a humanidade conseguiu desenvolver uma capacidade de produzir bens sem comparação com épocas passadas. As crises econômicas contemporâneas são provocadas pela superprodução de bens (com relação à demanda solvente), não pela sua insuficiência. Por outro lado, na medida em que o processo produtivo se desenvolve no contexto do mercado e da concorrência, o aumento da produtividade se impõe a quaisquer outras considerações. O fantástico desenvolvimento da tecnologia resultante desse processo tem assim uma dupla conseqüência: aumentar a produtividade e a produção e substituir o trabalho humano pela máquina. Cria-se assim o desemprego, flagelo contemporâneo que não possui - como às vezes se pretende - características conjunturais. Trata-se de desemprego estrutural, que, tendo por causa a lógica de organização vigente do processo produtivo, tende necessariamente a aumentar. Não se trata obviamente, nesta crítica, de ressuscitar o ludismo do começo da Revolução Industrial, mas de assinalar a racionalidade global de um sistema comandado pela racionalidade parcial dos interesses individuais e pela lógica da máquina produtiva. É obvio que o progresso técnico é, em si mesmo, positivo. Ele tem a capacidade potencial de libertar os homens do constrangimento dos trabalhos mais penosos, abrindo a possibilidade de imprevisíveis desenvolvimentos da criatividade humana. Mas para que isso seja possível é imprescindível que os bens produzidos sejam distribuídos de maneira a satisfazer as necessidades dos homens. Entretanto, a distribuição dos bens produzidos segundo critérios de mercado - isso é, mediados exclusivamente pela retribuição do trabalho - torna isso impossível, configurando a atual situação na qual a extraordinária riqueza produzida pela máquina produtiva determina o crescimento da desigualdade e a disseminação da miséria junto com o desemprego e o aumento da exploração do trabalho. Assim, é a lógica que rege a produção e a distribuição de bens que deve ser questionada, não o progresso tecnológico em si mesmo.

Em relação a esse progresso, parece inevitável que continue a aumentar aceleradamente. De um lado, porque a concorrência que rege o mercado faz da produção e incorporação de tecnologia a principal arma na luta pelo mercado. É, portanto, condição de sobrevivência para cada fração do capital. De outro, porque o extraordinário crescimento da ciência o incentiva de maneira espetacular. Basta citar Hobsbawm, que, no seu último livro (Era dos Extremos: o breve século $X X)$, apresenta os seguintes dados: se, no início do século, o número de físicos e químicos existentes na Alemanha e na Inglaterra era de aproximadamente oito mil, em 1980, o número de cientistas e engenheiros dedicados à pesquisa e ao desenvolvimento experimental era estima- 
do em cerca de cinco milhões. Esse processo de crescimento da capacidade científica e tecnológica continua inquestionavelmente a aumentar, de maneira que é perfeitamente legítimo prever que em poucas décadas estaremos muito perto da automatização quase geral do processo produtivo em múltiplas áreas da atividade econômica, com as inevitáveis conseqüências sobre a oferta de emprego. Essa será a realidade para a qual temos de nos preparar. Ela exigirá de nós uma enorme capacidade de invenção em relação às formas de distribuição dos bens produzidos e de organização da sociedade em um sentido mais geral. Parece-nos indiscutível que a ideologia e as práticas sociais vigentes, difundidas pelo discurso e pelas políticas neoliberais, estão longe de nos preparar para esse futuro.

Aumento da desigualdade, da exploração do trabalho, da marginalidade e da miséria, crescente descompasso entre as capacidades de produzir e de consumir da demanda solvente, irracionalidade crescente do conteúdo da oferta com relação às necessidades básicas da maior parte da humanidade, estas características ilustram a situação vigente no terreno da economia. Entretanto, entre as caraterísticas negativas desse modelo é preciso mencionar também suas conseqüências sobre as relações humanas. Cremos existir consenso em admitir a existência de um mal-estar específico na sociedade contemporânea. A sociedade do individualismo tem-se tornado também a sociedade da solidão, da intolerância e da xenofobia. A desagregação das formas tradicionais de organização social, por não ser acompanhada da emergência de outras formas de sociabilidade caracterizadas pela solidariedade, abriu espaço - no contexto da luta feroz pela sobrevivência - à notória expansão de atitudes e condutas narcísicas. A aparente ausência de alternativas a esse modelo social regido pelo darwinismo social, ausência enfatizada pela pregnância do discurso neoliberal - ainda mais crível devido ao fracasso e à derrubada dos regimes denominados de socialismo real - permitiu uma extraordinária expansão das atitudes que vêm no "salve-se quem puder" a única alternativa na luta pela sobrevivência.

A solidão e o desespero que resultam dessa situação se exprimem no sensível aumento de consumo de drogas (legais ou não) e do alcoolismo. De outro lado, o desemprego e o medo do desemprego incentivam o crescimento de atitudes xenófobas e intolerantes, acrescentando este tipo específico de violência à violência social provocada pela miséria. O tratamento dado a trabalhadores estrangeiros (tanto por muitos governos quanto por frações da população de numerosos países) constitui um dos aspectos mais claros da irracionalidade global vigente, tornando evidente a primazia outorgada aos 
interesses da máquina produtiva em detrimento dos interesses humanos. A globalização da economia impulsiona a integração de mercados, condicionando o crescimento econômico à livre circulação de mercadorias e capitais. Porém, o mesmo não ocorre com os homens, que, em maior medida do que nas décadas anteriores, sofrem crescentes restrições ao direito de se deslocarem entre países para procurar emprego - quando não são expulsos, sem nenhuma cerimônia, de países em que trabalharam e viveram durante anos. A ignorância do outro e de seus direitos e a rejeição da alteridade constituem uma perigosa característica da sociedade contemporânea. Ela exprime um déficit erótico - isto é, do laço que une e aproxima os homens - de conseqüências assustadoras. (Voltaremos brevemente a este assunto ao discutirmos a concepção neoliberal da natureza humana.)

Convém atentar para algumas questões que, apesar de evidentes, são com freqüência ignoradas, quiçá como conseqüência da hegemonia alcançada pelo discurso neoliberal. Em numerosos países, submetidos às políticas econômicas e sociais postuladas por essa ideologia, se aplicam atualmente políticas de 'racionalização' dos gastos públicos e de 'flexibilização' das relações de trabalho. As primeiras consistem invariavelmente na diminuição dos gastos sociais, levando a um processo de desmonte do Estado de bem-estar social. A flexibilização das relações de trabalho, por sua vez, constitui um eufemismo para aludir à anulação de numerosas conquistas sociais resultantes de décadas de luta das classes trabalhadoras. Todo isso no contexto de um acréscimo espetacular dos bens produzidos e da capacidade de produzir. Assim, porque estamos fantasticamente ricos como espécie, é necessário aumentar o tempo de trabalho (aumento da idade para aposentadoria), anular benefícios conquistados pelas mulheresmães trabalhadoras, diminuir gastos em educação, em saúde etc. Um exemplo mais preciso permitirá apreender na sua real dimensão as conseqüências dessa irracional organização da sociedade contemporânea. Como é sabido, quase todos os países reconhecem, nas suas legislações, direitos específicos das mulheres trabalhadores que são mães. Também é sabido que muitos empresários penalizam essas trabalhadoras, que encontram, assim, maiores dificuldades para obter emprego. De acordo com a racionalidade vigente, considera-se que seria benéfico para essas trabalhadoras se os mencionados direitos fossem anulados ou diminuídos, pois, desse modo, as mulheres encontrariam menos dificuldades para conseguir emprego. Cabe, então, perguntar, tendo como horizonte critérios de racionalidade - qual é a racionalidade de uma sociedade que, ignorando a fundamental importância da relação mãe-filho para a vida das pessoas, ao invés de privilegiá-la, torna-a mais difícil e precária? 
Em outro aspecto ainda a sociedade contemporânea evidencia o afastamento das promessas da modernidade. Trata-se da questão da política e da democracia, que exige uma reflexão sobre uma situação paradoxal. Com efeito, é possível constatar a substituição, nos últimos anos, de numerosos governos autoritários por governos representativos eleitos pelo voto popular. Isso constitui um fato positivo de valor inquestionável. Entretanto, ele é acompanhado de outras características contrárias, tais como o crescente desinteresse da população pela política, os níveis atingidos pela manipulação da opinião pública com o uso maciço dos meios de comunicação social e de técnicas sofisticadas de propaganda e a pregnância do discurso hegemônico com pretensões de discurso único.

O desinteresse crescente da população pelos processos políticos, verificado em numerosos países, parece obedecer a motivações complexas. Algumas delas, entretanto, podem ser aqui indentificadas. Assinalemos em primeiro lugar a expansão da mentalidade individualista já mencionada, que tende afastar as pessoas de questões relativas ao coletivo. Esta tendência vê-se reforçada pelas frustrações experimentadas no passado recente em diversos países, nos quais partidos políticos e políticos eleitos em função de defenderem determinado programa desenvolveram, uma vez no governo, políticas antagônicas àqueles programas. A isso deve acrescentar-se a pregnância do discurso neoliberal hegemônico, apresentado como o único científico e racional, e que nega de maneira intolerante quaisquer alternativas. A manipulação da opinião pública pelos meios de comunicação de massas e a utilização de sofisticadas técnicas de propaganda reforçam ainda esse processo. As dimensões atingidas por essa manipulação são realmente assustadoras. Elas permitem que fatos notórios e evidentes em si mesmos se transformem, por arte da manipulação, em seu contrário. O episódio da imprudente fala do então ministro Ricupero pela antena parabólica, por ocasião da campanha eleitoral que resultou na eleição do atual presidente no Brasil é, nesse sentido, exemplar. O ministro reconheceu, em uma entrevista que se tornou pública em rede nacional de televisão, que o governo a que pertencia sonegava e manipulava informação para favorecer seu candidato à presidência. Entretanto, a máquina de propaganda manipulou de tal maneira os fatos que, em poucas horas, o dito ficou por não dito, e quem assumira publicamente ter infringido a lei tornou-se a vítima daqueles cujos direitos legítimos foram violentados. A reprodução da fita contendo a entrevista de Ricupero foi censurada poucos dias após o fato ter ocorrido, e a própria fala foi apresentada como resultado do estresse e do cansaço provocados pela abnegada dedicação devotada à nação. Assim, o 
processamento que a propaganda fez do fato caracterizado pela fala do ministro veio a confirmar aquilo que ele próprio reconhecera involuntariamente na sua fala, isto é, a existência de uma extraordinariamente eficiente prática de manipulação da opinião pública.

Esse conjunto de fatos caracteriza uma situação que restringe de maneira notável as margens de escolha e decisão da cidadania. Não constitui obviamente uma fatalidade, mas coloca um desafio para a criatividade daqueles que, discordando do projeto e das políticas neoliberais, lutam por implementar políticas e projetos alternativos. Numerosas iniciativas de diversos segmentos da sociedade civil, assim como experiências desenvolvidas em municípios administradas por forças políticas progressistas, assinalam eficientes formas alternativas de luta política.

\section{Dimensões da Crise CONTEMPORÂNeA}

Apesar de breves, as considerações feitas indicam a existência de uma crise multifacetada. A lógica da máquina produtiva, tornada hegemônica em uma sociedade comandada pelas relações de mercado, se contrapõe de maneira crescente a uma racionalidade organizada em torno da obtenção dos valores fundadores da modernidade. É a negação do outro (cada vez mais reduzido à condição de objeto de consumo), e não a fraternidade, que rege a vida social. A manipulação, e não a liberdade, a marginalidade e a exclusão, ao invés da igualdade. A lógica da máquina produtiva, tornada onipotente pelo esvaziamento das funções do Estado, se estende a todos os aspectos da vida social, impondo a todos suas características constitutivas: a concentração, o primado do interesse individual ou setorial e a exploração. Assistimos a um inequívoco processo de concentração, que abrange desde a concentração da riqueza até a do poder, nos seus múltiplos aspectos. Essa lógica tende a atingir o conjunto das relações humanas, desde as relações com a natureza até as relações entre os homens, difundindo as práticas e a mentalidade predatórias. Assim, caracterizada pela irracionalidade, pela marginalização de milhões de homens e mulheres, pela miséria de massas, pelo desperdício e pela destruição da natureza, a civilização forjada pela modernidade tornou-se incapaz de realizar seu projeto e cumprir suas promessas.

Essa crise multifacetada, entretanto, inclui também a crise do paradigma moderno, e é em seu bojo que parece possível, rompendo a camisa de força na qual a modernidade aprisionou o pensamento, encontrar possibilidades de 
superação da atual situação. Nesta crise paradigmática, comparável pela sua profundidade e extensão à que presidiu a emergência da modernidade, tanto a concepção do real quanto a do conhecimento são submetidas a uma profunda transformação. Como se assinalou anteriormente, a modernidade concebia o real como estável, organizado conforme leis rigorosas e, portanto, como rigorosamente determinado. A essa ontologia do ser, os saberes contemporâneos opõem uma ontologia do devir, caracterizada pela transformação e pela auto-poiésis. Nesta concepção, o determinismo caracteriza apenas setores do real, extremamente complexo, marcado pela indeterminação e pela emergência do novo. Esta nova concepção ontológica é acompanhada de uma nova perspectiva epistemológica. À crise do paradigma corresponde a crise de suas condições de inteligibilidade. Assim, não é apenas o real que é pensado como complexo, mas também o sujeito. A crítica da racionalidade postulada no objeto é acompanhada pela crítica do racionalismo atribuída ao sujeito de conhecimento, isto é, pela crítica da unilateralidade da concepção forjada pela modernidade sobre o homem.

O caráter de necessidade atribuído à situação presente pelo pensamento hegemônico se sustenta na premissa de determinação que preside a concepção do mundo da modernidade. Pensando o homem como naturalmente orientado para a maximização de seus interesses individuais, o paradigma moderno concebe a concorrência entre os homens como a forma 'natural' e, portanto, necessária, de organizar a vida social. Qualquer outro projeto, concepção ou alternativa é visto, de acordo com essa perspectiva, como uma utopia irrealizável, fadada ao fracasso. Entretanto, essa maneira extremadamente simplificada de conceber o fenômeno humano não se sustenta à luz dos saberes contemporâneos. Assim, o saber produzido pela psicanálise, longe de pensar o homem como constituindo 'naturalmente' uma máquina de procurar 'racionalmente' a satisfação de seus interesses individuais, o apresenta na sua extrema complexidade como dotado de uma grande plasticidade psíquica e como, em grande parte, resultado de sua história.

Entretanto, nem tudo é história na concepção freudiana do homem. Considerado, basicamente, como um ser de afetos, a psicanálise vê o homem impulsionado por forças conflitantes, que recebem na teoria as designações de pulsão de vida e de morte. A primeira, denominada pulsão erótica, supõe o reconhecimento do outro e o movimento de unir-se a ele. A segunda caracteriza um movimento de separação e agressividade. É nas vicissitudes da história que o conflito entre esses movimentos, em si mesmo insuperável, adquire suas múltiplas formas possíveis. São as práticas sociais históricas, em conse- 
qüência, que concedem a primazia a um ou outro movimento pulsional, em um processo infindável no qual qualquer equilíbrio permanente deve ser excluído. Assim, práticas sociais - e o discurso é uma prática social - que incentivam e impulsionam comportamentos individualistas, agressivos e de negação do outro produziram um certo tipo de homem, ao passo que práticas sociais caracterizadas pelo reconhecimento do outro favoreceram o fortalecimento do movimento erótico também presente no psiquismo humano. Reencontramos assim, na teorização psicanalítica, a famosa afirmação de Marx segundo a qual a "natureza humana" é o resultado do conjunto das relações sociais que os homens estabelecem entre si em cada momento histórico. O saber sobre o homem produzido pela psicanálise desautoriza qualquer otimismo em torno da possibilidade de ascender a uma organização social isenta de conflitos. Sustenta, todavia, a possibilidade da expansão de relações solidárias e de uma organização social democrática impulsionada pelo movimento erótico que procura o reconhecimento e a unidade. Esse saber sobre o homem, produzido por meio de práticas de conhecimento que fogem dos estreitos limites do racionalismo da modernidade, fornece uma outra concepção sobre o fenômeno humano, superando a limitada perspectiva racionalista. Podemos, assim, indicar um caminho de resposta para a primeira interrogação formulada no início deste artigo. É nesta perspectiva que convém agora desenvolver algumas considerações em torno da concepção antropológica do marxismo, de maneira a nos aproximar de uma resposta às duas outras questões levantadas em torno do sujeito.

Embora constitua um poderoso instrumento teórico para a compreensão da vida social, não acreditamos ser pertinente repetir hoje a fórmula sartriana, segundo a qual o marxismo representaria o horizonte científico do nosso tempo. Constituindo a expressão mais conseqüente do pensamento iluminista segundo afirma Engels -, a concepção antropológica postulada pela teorização marxista funciona como um verdadeiro obstáculo epistemológico. O racionalismo que preside essa concepção encerra, de fato, uma idéia de necessidade. Com efeito, como seres racionais, os homens deveriam escolher formas de organização social que possibilitassem a organização mais racional das relações dos homens com a natureza e dos homens entre si. Se não o fazem é porque, alienados pela ideologia dominante na sociedade de classes, enxergam a realidade sob a forma deturpada produzida por essa ideologia. Entretanto, a substituição dessa perspectiva ideológica por outra, produzida pelo trabalho científico e político, permitiria superar tal alienação, transformando o proletariado de classe em si, ignorante de sua força e de seus interesses, em 
classe para si, consciente de ambos. O processo revolucionário, capaz de instalar a racionalidade na vida social, passa então pela difusão da perspectiva científica entre o proletariado, na sua organização como sujeito coletivo da transformação social, pela mudança das relações sociais de produção capitalista que esse sujeito coletivo implementaria e pela difusão da racionalidade no conjunto da vida social. O resultado final seria uma sociedade sem conflitos, que poderia prescindir do Estado pensado como instrumento de poder e arbitragem, substituindo a administração dos homens, própria da sociedade de classes, pela administração das coisas.

Projeto belíssimo, sem dúvida, que inspirou a luta generosa de milhões de homens e mulheres. Porém, projeto primo-irmão do mito do progresso iluminista e, como este, incapaz de apreender a complexidade do homem e das forças e processos através dos quais os homens produzem a história. Como já afirmamos, há nessa concepção uma idéia de necessidade histórica e, portanto, de determinismo Não de determinismo economicista, como as críticas levianas ou interessadas e as vulgarizações teóricas difundiram. Na perspectiva de Marx, a base econômica era vista como condicionante da vida dos homens, não como determinante; ele pôde assim afirmar, como fez na Ideologia Alemã e nas Teses sobre Feuerbach, que os homens são aos autores de sua própria história.

Entretanto, outro determinismo marca o pensamento marxista, fundamentado na expansão inevitável da racionalidade. Nesse processo necessário, o sujeito seria coletivo e seria o proletariado. Duas ordens de considerações fundamentam essa concepção: uma de ordem empírica, outra de ordem teórica. A primeira diz respeito à expansão numérica do proletariado, resultante da lógica econômica do capitalismo e constatada empiricamente na época de Marx. E ainda ao crescimento - constatado por Marx - da alfabetização do proletariado, impulsionada inicialmente pelo trabalho de suas próprias organizações e também pela expansão da escolaridade nos países mais avançados. Tanto essa expansão quanto a forma como ela era realizada - pensava Marx - produziriam a formação de uma consciência autônoma do proletariado, autônoma com relação à ideologia burguesa e, portanto, isenta da contaminação dessa ideologia. A crença de Marx, segundo a qual o processo histórico, no contexto da expansão das forças produtivas sob o capitalismo, levaria à constituição de uma consciência autônoma do proletariado, não contaminada nem muito menos subordinada à ideologia gerada perla sociedade burguesa, não se verificou.

Múltiplos aspectos deveriam ser considerados para se entender esse fato. Aqui, nos limitaremos a assinalar que o processo de difusão da escolaridade, assim como dos meios de comunicação de massa e mesmo do consumo, 
acabou por atrelar a formação do proletariado ao movimento geral da sociedade, 'hegemonizada' pela ideologia burguesa. Isso é óbvio hoje, dada a influência da televisão e do rádio. Porém, a mudança da situação - com respeito à analisada por Marx - se verificara bem mais cedo. De fato, se os operários da época de Marx liam a imprensa sindical e socialista - e muitas vezes aprendiam a ler com ela -, as gerações seguintes, de maneira progressiva, tinham acesso a publicações produzidas conforme a mentalidade hegemônica na sociedade. Mais importante ainda foi a mudança operada em torno do processo de proletarização. A expansão do capital, embora tenha eliminado progressivamente os pequenos proprietários, após um primeiro período de expansão numérica do proletariado, e na medida em que aumentava a introdução de tecnologia no setor secundário da economia, propiciou um crescente processo de diferenciação dos trabalhadores, diminuindo a percentagem dos operários na população assalariada. Como se sabe, não é apenas o fato da exploração ou de ser assalariado que interessa na concepção do papel que cabe à sociedade e ao processo produtivo. As modalidades do processo de trabalho, o tipo de ocupação e até a forma de vestir que a função exige têm importância na maneira como as pessoas percebem a si mesmas. Assim, não é incomum que trabalhadores que recebem remunerações inferiores aos que trabalham na indústria de transformação, pelo fato de não usarem macacão e de realizarem determinados serviços, se considerarem situados em um nível social 'superior' ao dos operários da indústria.

Entretanto, se os dois fatores mencionados - e muitos outros não abordados aqui - mudaram a realidade que geraria o proletariado como sujeito autônomo e consciente, outro fator, este de ordem teórica, permite compreender o fracasso da previsão marxista. Trata-se do racionalismo e da sua contrapartida - a ignorância da participação decisiva dos afetos no psiquismo humano e, portanto, na formação dos sujeitos sociais. O comportamento dos proletariados francês e alemão por ocasião da Primeira Guerra Mundial ilustra bem este ponto. Essa guerra era compreendida pelo pensamento socialista da época como um conflito 'interburguês' e 'interimperialista', alheio às motivações e interesses dos proletários. Por isso, o pensamento socialista era contrário à guerra e defendia bandeiras pacifistas. Todavia, para surpresa dos poucos dirigentes socialistas que permaneceram fiéis a essas idéias, o sentimento patriótico da maior parte dos proletários dos dois países os levou a apoiar suas respectivas burguesias e a participar de uma guerra na qual seriam as principais vítimas. 
Cabe, então, perguntar por que a teoria não foi capaz de pensar a questão e de fazer uma previsão mais pertinente. O que estava em jogo, na verdade, era o sentimento de participação em um 'nós' coletivo, organizado em torno da idéia de nação. Múltiplos aspectos participam na constituição desse sentimento de nacionalidade, que possui - especialmente em momentos históricos de alta densidade emocional - uma força de motivação que tem se mostrado mais forte e decisiva do que qualquer compreensão racional. A significação da idéia e do sentimento de nação simplesmente não foi apreendida pela teorização marxista, que preferiu privilegiar outro importante aspecto: o mercado nacional como terreno reservado pela burguesia de cada país. Não há dúvida de que esse aspecto foi fundamental na constituição e na história dos países. Todavia, isso não autoriza a ignorar os outros aspectos que estão em jogo quando se fala em nação, aspectos que não são do registro da economia, mas pertencem ao registro dos afetos, crenças e sentimentos.

A tarefa de reproduzir as condições da vida material responde obviamente à necessidade humana mais premente. Nessa esfera da vida social se processam, em conseqüência, relações sociais, formas de organização e conflitos de primeira importância. Na perspectiva do sujeito coletivo, o que se forma nas atividades vinculadas à vida econômica constitui sem dúvida um sujeito central. Entretanto, afirmar que os trabalhadores constituem um sujeito central não significa afirmar que o proletariado é a classe que, por encarnar o sentido da história, constitui necessariamente a vanguarda do processo histórico, devendo subordinar a todos os outros sujeitos coletivos. Esta última perspectiva encerra uma compreensão determinista da história, segundo a qual o comunismo, por ser a forma de organização mais racional, seria necessariamente construído. Observe-se que, conforme já assinalamos, o determinismo subjacente a tal perspectiva elimina de fato a idéia de criatividade, aprisionando o conceito de história nas margens estreitas do teleologismo. As ciências e os saberes contemporâneos desautorizam tal determinismo. Os saberes contemporâneos sobre o homem e, em particular, a psicanálise, longe de confirmarem a perspectiva que o define a partir de sua racionalidade, expõem a extrema complexidade de suas motivações e objetivos. É essa pluralidade que está na base das múltiplas formas de organização que homens e mulheres constroem na vida social. Movimentos sociais, por vezes mal denominados 'de minorias', privilegiam determinado aspecto da vida social e individual, constituindo sujeitos sociais coletivos específicos. Os objetivos desses sujeitos coletivos não se confundem com os objetivos do sujeito coletivo que se organiza em torno da esfera da produção nem a eles se 
subordinam, embora muitas vezes os múltiplos objetivos possam e devam articular-se entre si. Assim, os movimento feminista, negro, das 'minorias sexuais', ecológico etc. não constituem formas secundárias de organização do sujeito coletivo nem se ocupam de problemas que teriam solução automática em uma sociedade socialista.

Cada um desses movimentos se organiza em torno de relações sociais específicas nas quais se processam formas também específicas de dominação, exploração, negação de direitos etc. E, obviamente, quanto mais complexas se tornam a sociedade e as relações sociais que nela se organizam, mais se multiplicam os 'campos' de atuação e as condições de emergência de novas modalidades de organização do sujeito social. Se o sujeito social deve ser pensado como 'plural', a organização dos sujeitos coletivos parciais que atuam nos diversos níveis de relações sociais não pode operar pela via da subordinação, mas da coordenação. Sujeito plural, mas também sujeito de criação e, portanto, sujeito da diferença. Com efeito, a crise do paradigma da modernidade significa abandonar a idéia de uma ordem necessária e de um processo histórico determinado. Assim, a história não se realiza, mas se cria em um processo em que a emergência do novo exige a aceitação da diferença. Estas considerações em torno do sujeito coletivo plural e do sujeito da diferença fornecem alguns dos instrumentos teóricos necessários para se considerar a segunda e a terceira questão abordadas no início deste texto.

Vivemos uma época singular. Desencantada e sem utopias, o novo nela parece reduzir-se ao terreno da invenção tecnológica. Fascinado, e ao mesmo tempo amedrontado, o homem contemporâneo parece cada mais incapaz de pensar os desafios resultantes de sua própria ação, orientada pela razão instrumental. Prisioneiro da máquina produtiva por ele mesmo criada - o novo fetiche - obrigando-se a sacrificar por ele seus valores mais caros - solidariedade, fraternidade, compaixão -, o homem contemporâneo se condena em larga medida a abandonar seus sonhos, projetos e utopias de um mundo melhor. Essa triste e estéril representação da realidade se funda em uma perspectiva determinista que não encontra sustento nas ciências e nos saberes contemporâneos. Longe de afirmar a inexorabilidade de leis naturais a determinar o curso da história e as motivações da ação humana, essas ciências e saberes reintroduzem a perspectiva da criação e da utopia. Mostram, assim, a possibilidade mas também o desafio de um pensamento e de uma racionalidade diferentes. Racionalidade não mais pautada apenas no 'como', mas também no 'para quê'. Racionalidade que não mais confunde o real existente com o 
real natural. Racionalidade plural, feita de múltiplas racionalidades, coordenadas por uma perspectiva humanista centrada no respeito pela vida e pelas suas também múltiplas e criativas manifestações.

As ciências e os saberes contemporâneos derrubaram a metáfora que pensava o real como constituindo uma máquina determinada pelas suas leis de constituição. Alternativamente, sugerem outra concepção segundo a qual o real é pensado por meio de metáforas que o aproximam de um organismo vivo, criativo e inter-relacionado por formas que excedem largamente a relação causal, única reconhecida pelo paradigma da modernidade. As idéias centrais nesta concepção emergente do real são as de criatividade e interrelacionamento - as relações entre as partes constituindo as singularidades de cada uma delas. Esta perspectiva, quando utilizada para pensar o homem, obriga a superar o individualismo da modernidade e a associar o desenvolvimento da singularidade de cada indivíduo a seu relacionamento solidário com os outros e com a natureza.

A evolução da doutrina sobre os direitos humanos acompanha esse processo. Surgida no contexto da afirmação do indivíduo diante do arbítrio do poder estatal, tal doutrina afirmou inicialmente os direitos civis e políticos. Posteriormente, no bojo da preeminência e da premência da questão social, foram cunhados os direitos sociais e econômicos. Se os direitos humanos de 'primeira geração' apontavam para uma limitação do poder estatal, os de 'segunda geração' sustentavam a obrigação da sociedade e do Estado de garantir a todos o acesso aos bens e serviços indispensáveis para uma vida digna. Mais recentemente ainda, o reconhecimento do caráter constitutivo das relações dos homens com a natureza levou à proclamação dos diretos humanos de 'terceira geração', entre os quais podemos destacar o direito à preservação do meio ambiente. Assim, o reconhecimento das diversas categorias de direitos humanos resultam de um processo de conquistas progressivas. Trata-se de um processo aberto, não concluído. Ele não se limita a reconhecer determinados dados da natureza, mas a criar novos direitos, emergentes da ação criativa dos homens e da afirmação da multiplicidade e da diferença. É um processo aberto no qual, paradoxalmente, é preciso superar a perspectiva do paradigma da modernidade para poder realizar uma de suas concepções centrais, a historicidade. Proclamada, porém ao mesmo tempo esvaziada pelo determinismo também constitutivo do paradigma moderno, a historicidade é recuperada no paradigma emergente, abrangendo não apenas a experiência dos homens mas também o processo da natureza. 